\title{
Strox: A 3-year study of intoxicated cases admitted to Poison Control Center Ain Shams University Hospitals
}

\author{
Hany Mohamed Tawfik ${ }^{1}$
}

${ }^{1}$ Poisoning Control Center, Faculty of Medicine-Ain Shams University, Cairo Egypt.

Key words Strox, coma, agitation, liver, cardiac, mortality

\section{Introduction}

B esides traditionally abused substances, the use of the new psychoactive substances (NPS) is an alarming global problem that has become more marked in the last few decades (Lamy et al., 2017). NPS can be categorized into four groups: synthetic stimulants, synthetic hallucinogens, synthetic depressants, and synthetic cannabinoids. Despite the great efforts that have been made to diminish their skyrocketing use, the number of NPS is still increasing together with the number of users (Shafi et al., 2020).

Synthetic cannabinoids (SCs) are either sprayed on dried plant material so they can be smoked or sold as liquids to be vaporized and inhaled in electronic cigarettes. Their types are variable from country to another and their constituents are subjecting to continues renewing by their creators to escape legal prohibition (Farquhar et al., 2018).

An emerging novel synthetic cannabinoid that named Strox is representing great medical and legal challenges in Egypt. SCs bind to the cannabinoid type1 (CB1) and type-2 (CB2) receptors and produce their psychoactive and behavioral effects via CB1 receptor agonism (Atwood et al., 2011). As with tetra-hydrocannabinol (THC), prolonged exposure to SCs results in tolerance to agonist effects, decreased CB1 receptor expression and signaling in specific brain regions (Tai et al., 2015).
Strox synthesis is an easy process that made it available with low prices in comparison with cannabis. Furthermore, the standard toxicology screens could not identify Strox users whereas natural cannabis would be traced (Sobh and Sobh, 2020). Strox-related toxicity could be attributed to THC, anticholinergic agents, and additives such as ketamine. Strox toxicity can occur without overdose because the type and amount of cannabinoid are varying considerably from batch to batch even within the same product (Tellioglu, 2018).

Acute Strox intoxication usually present with visual and auditory hallucinations, irritability, fear, and anxiety accompanied with intense aggression. Moreover, clinical effects mimicking anticholinergic toxidrome could occur after Strox smoking such as dilated pupil, increased heart rate, and dry flushed skin. Sever toxic effects can occur including respiratory depression, cardiac events including cardiac arrest, nephrotoxicity, seizures, and deep coma (Lapoint et al., 2011).

Acute Strox intoxication is frequently treated with supportive care and intravenous fluids to treat electrolyte and fluid disturbances. Cases with irritability, agitation, anxiety, and seizures are generally managed by benzodiazepines as a first-line treatment. Neuroleptics are also administered for acute 
psychosis and agitation. Antiemetics have been administered for hyperemesis (Ziva, 2016).

\section{Objective:}

The study aimed to study the socio-demographic, clinical characteristics and causes of deaths in patients with acute Strox toxicity who presented to Poison Control Center Ain Shams University Hospitals (PCC-ASUHs).

\section{Patients and Methods:}

This study was a cross sectional observational study carried out over a three-year duration; prospectively during (2019-2020) and retrospectively during 2018. The study included all cases of acute Strox toxicity admitted to the Poison Control Center of Ain Shams University Hospitals (PCC-ASUHs). The diagnosis of Strox toxicity was based on history of exposure and/or the presence of characteristic clinical symptoms and signs (Bozkurt et al., 2014).

Exclusion criteria included patients with multiple drugs overdose, positive drug abuse screen, history of liver, renal, pulmonary, cardiac, neurological, endocrinal, or immunological diseases.

An informed written consent was taken from the patient or his/her legal guardian. Approval of the Head of PCC-ASUHs was obtained. Data were collected with consideration of confidentiality issues.

For the prospective study during the year 2019 and 2020, patients were subjected initially to complete medical history including: age, gender, route and mode of exposure from patients or his/her relatives, followed by measuring vital data and complete systemic examination.

Laboratory analysis were done on admission and repeated during the patient stay as needed including arterial blood gases (ABG), liver function tests (LFT) and renal function tests (RFT). Electrocardiogram (ECG) was done for all patients on admission and repeated as indicated.

Management and hospital disposition was done according to the patient's condition and according to the protocol of management in PCC-ASUHs. Patients with central nervous systems manifestations, hemodynamic instability, respiratory distress, or cardiac arrhythmia were admitted to the ICU department. Outcome data were recorded including duration of hospital stay, intensive care unit (ICU) admission, occurrence of complications as; cardiac arrhythmia and decompensating respiratory failure, renal impairment, liver impairment and mortality rate.

Based on survival, patients were classified into two groups: group I (survivors including 82 patients) and group II (non-survivors including 10 patients).

Statistical Analysis: The results were statistically analyzed using the SPSS software, version 17 (SPSS, Inc., Chicago, IL). Quantitative data are described as mean \pm standard deviation (SD) and qualitative data are described as number and percentage. Chi-square test $(\chi 2)$ was used to evaluate the differences between both groups. $\mathrm{P}$ values $<0.05$ were considered statistically significant (Taylor, 1990). Results:

Table (1): Age and Sex distribution in both studied groups.
This study included 92 patients presented to PCCA with Strox toxicity over 3 years period from beginning of the year 2018 to end of the year 2020 . Table (1) showed that 9 patients $(9.8 \%)$ were in the age group $<13$ years, 76 patients $(82.6 \%)$ were in the age group between $13-40$ years and 7 patients $(7.6 \%)$ above 40 years. Males constituted the majority of cases (93.5\%). Eighty three patients $(90.2 \%)$ were intoxicated due to addiction while 9 patients $(9.8 \%)$ were accidental. Eighty patients $(90.2 \%)$ were by smoking (Tables 2). Statistical analysis revealed no significant differences between survivors and nonsurvivors as regard age, sex, and mode/route of poisoning.

As regard vital data and clinical presentation table (3) showed that 20 patients (22\%) had abnormal heart rate, 11 patients $(12 \%)$ had shock and 29 patients $(32 \%)$ had respiratory distress. Fifty eight patients $(63 \%)$ had coma, 31 patients $(34 \%)$ had agitation, 15 patients $(16 \%)$ had seizures, 30 patients $(33 \%)$ had vomiting, and 20 patients $(22 \%)$ required mechanical ventilation and $4.3 \%$ developed ECG abnormalities. Statistical analysis revealed significant increase in shock, respiratory distress, mechanical ventilation and arrhythmia in non-survivors.

As regard laboratory abnormalities table (4) showed 21 patients (23\%) had respiratory acidosis, 15 patients $(16 \%)$ had metabolic acidosis, 5 patients $(5 \%)$ had abnormal liver function tests and 3 patients $(3 \%)$ had abnormal renal function test. Statistical analysis revealed significant increase in metabolic acidosis and liver impairment in non-survivors.

The results revealed that the period of stay in the hospital were < 1day in 53 patients $(58 \%)$, from $2-4$ days in 33 patients $(36 \%)$ and more than7 days in 4 patients (4\%), Moreover, no significant differences was found between both groups as regards period of stay (table 5). Also the results revealed that 72 patients $(78.3 \%)$ were severe requiring ICU admission, while 20 patients $(21.7 \%)$ were mild to moderate and hence admitted in the inpatient ward (table 6).

Recorded overall in-hospital mortality was $11 \%$ (10 cases). Causes of mortality included cardiogenic shock (5 cases), adult respiratory distress syndrome (ARDS) in 3 cases, and respiratory depression leading to bradypnea and respiratory failure not responding to mechanical ventilation (2 cases). As regards nonsurvivors due to cardiogenic shock, 4 patients presented with chest pain irritability and agitation then developed shock and cardiac arrhythmia. Recorded ECG abnormalities included right bundle branch block, ventricular tachycardia (VT), sinus tachycardia and rapid atrial fibrillation followed by VT. The $5^{\text {th }}$ patient (child) presented with extrapyramidal manifestations and laryngospasm, mechanically ventilated, then developed ventricular fibrillation. 


\begin{tabular}{|c|c|c|c|c|c|}
\hline & $\begin{array}{c}\text { Survivors } \\
\mathbf{N}(\%)\end{array}$ & $\begin{array}{c}\text { Non-survivors } \\
\mathbf{N}(\%)\end{array}$ & $\begin{array}{l}\text { Total } \\
\text { N }(\%) \\
\end{array}$ & $\begin{array}{c}\text { Chi-square test } \\
\left(\chi^{2}\right)\end{array}$ & $\mathbf{P}$ \\
\hline \multicolumn{6}{|c|}{ Age/ year } \\
\hline$<13$ & $8(9.8 \%)$ & $1(10 \%)$ & $9(9.8 \%)$ & \multirow{3}{*}{2.4} & \multirow{3}{*}{0.2} \\
\hline $13-40$ & $69(84.2 \%)$ & $7(70 \%)$ & $76(82.6 \%)$ & & \\
\hline$>40$ & $5(6 \%)$ & $2(20 \%)$ & $7(7.6 \%)$ & & \\
\hline \multicolumn{6}{|l|}{ Sex } \\
\hline Male & $76(92.7 \%)$ & $10(100 \%)$ & $86(93.5 \%)$ & \multirow{2}{*}{0.7} & \multirow{2}{*}{0.3} \\
\hline Female & $6(7.3 \%)$ & 0 & $6(6.5 \%)$ & & \\
\hline
\end{tabular}

Table (2): Manner of poisoning of both studied groups.

\begin{tabular}{|c|c|c|c|c|c|}
\hline & $\begin{array}{c}\text { Survivors } \\
\text { N }(\%)\end{array}$ & $\begin{array}{c}\text { Non-survivors } \\
\mathbf{N}(\%)\end{array}$ & $\begin{array}{l}\text { Total } \\
\text { N }(\%)\end{array}$ & $\begin{array}{c}\text { Chi-square } \\
\text { test }\left(\chi^{2}\right)\end{array}$ & $\mathbf{P}$ \\
\hline \multicolumn{6}{|c|}{ Manner of poisoning } \\
\hline Accidental & $8(9.8 \%)$ & $1(10 \%)$ & $9(9.8 \%)$ & \multirow{2}{*}{0.001} & \multirow{2}{*}{0.9} \\
\hline Intended & $74(90.2 \%)$ & $9(90 \%)$ & $83(90.2 \%)$ & & \\
\hline \multicolumn{6}{|c|}{ Route of poisoning } \\
\hline Oral & $8(9.8 \%)$ & $1(10 \%)$ & $9(9.8 \%)$ & \multirow{2}{*}{0.001} & \multirow{2}{*}{0.9} \\
\hline Smoking & $74(90.2 \%)$ & $9(90 \%)$ & $83(90.2 \%)$ & & \\
\hline
\end{tabular}

Table (3): Vital signs and Clinical presentation in both studied groups.

\begin{tabular}{|c|c|c|c|c|c|}
\hline & $\begin{array}{c}\text { Survivors } \\
\mathrm{N}(\%) \\
\end{array}$ & $\begin{array}{c}\text { Non-survivors } \\
\mathbf{N}(\%)\end{array}$ & $\begin{array}{r}\text { Total } \\
\text { N }(\%) \\
\end{array}$ & $\begin{array}{c}\text { Chi-square } \\
\text { test }\left(\chi^{2}\right)\end{array}$ & $\mathbf{P}$ \\
\hline \multicolumn{6}{|l|}{ Vital signs } \\
\hline Abnormal heart rate & $16,(19.5 \%)$ & $4,(40 \%)$ & $20(22 \%)$ & 2.1 & 0.1 \\
\hline Abnormal blood pressure & $7,(8.5 \%)$ & $4,(40 \%)$ & $11(12 \%)$ & 8.3 & $0.003 *$ \\
\hline Abnormal respiratory rate & $21,(25.6 \%)$ & $8(80 \%)$ & $29(32 \%)$ & 12.2 & $0.0004^{*}$ \\
\hline \multicolumn{6}{|l|}{ Clinical presentation } \\
\hline Coma & $54(65.9 \%)$ & $4,(40 \%)$ & $58,(63 \%)$ & 2.5 & 0.1 \\
\hline Agitation & $29(35.4 \%)$ & $2(20 \%)$ & $31(34 \%)$ & 0.9 & 0.3 \\
\hline Seizure & $14(17 \%)$ & $1(10 \%)$ & $15(16 \%)$ & 0.3 & 0.5 \\
\hline Vomiting & $28(30 \%)$ & $2(20 \%)$ & $30(33 \%)$ & 0.8 & 0.3 \\
\hline $\begin{array}{l}\text { Respiratory failure needed } \\
\text { mechanical ventilation }\end{array}$ & $12(34 \%)$ & $8(80 \%)$ & $20(22 \%)$ & 22.3 & $0.0002 *$ \\
\hline Arrhythmia & 0 & $4(40 \%)$ & $4(4.3 \%)$ & 34 & $0 *$ \\
\hline
\end{tabular}

Table (4): Laboratory abnormalities in both studied groups.

\begin{tabular}{|c|c|c|c|c|c|}
\hline & $\begin{array}{c}\text { Survivors } \\
\mathbf{N}(\%) \\
\end{array}$ & $\begin{array}{c}\text { Non-survivors } \\
\mathbf{N}(\%) \\
\end{array}$ & $\begin{array}{l}\text { Total } \\
\text { N }(\%) \\
\end{array}$ & $\begin{array}{c}\text { Chi-square } \\
\text { test }\left(\chi^{2}\right)\end{array}$ & $\mathbf{P}$ \\
\hline Respiratory acidosis & $18(22 \%)$ & $3(30 \%)$ & $21(23 \%)$ & 0.3 & 0.5 \\
\hline metabolic acidosis & $10(12.2 \%)$ & $5(50 \%)$ & $15(16 \%)$ & 9.3 & $0.002 *$ \\
\hline Liver function tests & $2(2.4 \%)$ & $3(30 \%)$ & $5(5 \%)$ & 13.1 & $0.0002 *$ \\
\hline Renal function tests & $2(2.4 \%)$ & $1(10 \%)$ & $3(3 \%)$ & 1.6 & 0.2 \\
\hline
\end{tabular}

Table (5): Period of stay in both studied groups.

\begin{tabular}{|l|c|c|c|c|c|}
\hline Period of stay & $\begin{array}{c}\text { Survivors } \\
\mathbf{N}(\boldsymbol{\%})\end{array}$ & $\begin{array}{c}\text { Non-survivors } \\
\mathbf{N}(\boldsymbol{\%})\end{array}$ & $\begin{array}{c}\text { Total } \\
\mathbf{N}(\boldsymbol{\%})\end{array}$ & $\begin{array}{c}\text { Chi-square test } \\
\left(\chi^{\mathbf{2}}\right)\end{array}$ & $\mathbf{P}$ \\
\hline 1 day & $46(50.1 \%)$ & $7(70 \%)$ & $53(58 \%)$ & 0.7 & 0.4 \\
\hline 2-4 days & $31(37.8 \%)$ & $2(20 \%)$ & $33(36 \%)$ & 1.2 & 0.2 \\
\hline 5-7days & $2(2.4 \%)$ & 0 & $2(2 \%)$ & 0.2 & 0.6 \\
\hline$>7$ days & $3(3.7 \%)$ & $1(10 \%)$ & $4(4 \%)$ & 0.8 & 0.3 \\
\hline
\end{tabular}


Table (6): Hospital disposition in both studied groups.

\begin{tabular}{|l|c|c|c|c|c|}
\hline & $\begin{array}{c}\text { Survivors } \\
\mathbf{N}(\mathbf{\%})\end{array}$ & $\begin{array}{c}\text { Non-survivors } \\
\mathbf{N}(\boldsymbol{\%})\end{array}$ & $\begin{array}{c}\text { Total } \\
\mathbf{N}(\mathbf{\%})\end{array}$ & $\begin{array}{c}\text { Chi-square test } \\
\left(\chi^{2}\right)\end{array}$ & $\mathbf{P}$ \\
\hline Intensive care unit & $62(75.6 \%)$ & $10(100 \%)$ & $72(78.3 \%)$ & 3.1 & 0.07 \\
\hline Inpatient & $\mathbf{2 0}(\mathbf{2 4 . 4 \% )}$ & $\mathbf{0}$ & $\mathbf{2 0}(\mathbf{2 1 . 7 \% )}$ & 3 & \\
\hline
\end{tabular}

$P$-value $\leq 0.05$ statistically significant $\quad N=$ number $\%=$ percentage

\section{Discussion}

Synthetic cannabinoids use continues to be a significant public health concern. In the year 2018, Egyptian law incriminated usage of THC analogues which was rapidly followed by alteration of its constituents by providers using non-prohibited cannabinoids to escape legal prohibition. Attention to the dangers of SCs has been largely due to the severe, life-threatening toxic effects described in case reports and several studies (Cooper, 2016).

In the current study, the majority of the patients were males $(93.5 \%)$, in the age between $13-40$ years $(82.6 \%)$, mainly intoxicated following smoking due to addiction $(90.2 \%)$. Statistical analysis revealed no significant differences between survivors and nonsurvivors as regard age, sex, manner of poisoning and route of poisoning. Similar results obtained by Oznur et al. (2018) in their study of 166 patients with SCs use where the age onset for SCs use was $17.25 \pm 2.30$ years, all the patients were males, and consumption of SCs was through inhalation $(76.5 \%)$ or through oral route (22.9\%). Moreover, a Turkish research on 158 SCs users by Bozkurt et al. (2014) revealed that $94.9 \%$ of SCs users were men, with mean age of $26.1 \pm 7$ year. Similarly, Murat et al. (2018) reported 340 SCs users in a 3-month period and found that the mean age of the SCs users was $26.8 \pm 7.5$ years and $92.6 \%$ were men. Also, Marc et al. (2017) found that $95.5 \%$ were male and addiction was by inhalation. The higher rate of drug abuse in this age group can be attributed to life burden, psychological disturbances, stresses due to difficulty getting a job and marriage leading to involvement in drug abuse. (Jesslin et al., 2010). The prevalence of abuse among males can be related to the fact that males usually show external aggressive behaviors in dealing with problems in contrast to females who show autoaggressive behavior. Consequently, suicide is more common in females and addiction is more common in males (Schepis et al., 2011).

In the present study, central nervous system manifestations were predominant as $63 \%$ of patients developed coma, 34\% developed agitation, and $16 \%$ had seizures. Similarly, Oznur et al. (2018) in their study of SCs user found that $74.1 \%$ of the patients developed hallucination, and $11.4 \%$ developed seizures. Also, Sarah et al. (2019) in their study of 107 patients with SCs abuse found that $28.5 \%$ of the patients had coma, $23.5 \%$ had agitation, $19 \%$ had seizures and $7 \%$ had hallucination. Murat et al. (2018) recorded psychotic symptoms in $78.8 \%$ of SCs users and impaired consciousness $42.3 \%$ was the most common reason for referral to the general hospital. Disturbed conscious level may be related to inhalation of xylene (aromatic hydrocarbon) added to Strox preparations which burns easily and known for its central depressant effect. While anxiety, agitation and seizures may be related to Activation of cannabinoid receptors $\mathrm{CB} 1$ which decreased $\mathrm{GABA}$ release and results in reduced excitation and suppressed inhibition (Armstrong et al., 2019). In the current study, vomiting was noted in $33 \%$ of the patients and $32 \%$ had respiratory distress and most of them (22\%) were mechanically ventilated. Similarly Oznur et al. (2018) in their study found that $62 \%$ of the SCs users had respiratory distress and $53 \%$ had vomiting.

Associated vomiting can be attributed to inhibitory effect off SCs on electrically induced contractions of small intestine causing delayed solidphase gastric emptying. Thus, repetitive vomiting and abdominal pain are prominent gastrointestinal symptoms among SCs abusers (Robinson et al., 2013). Regarding associated respiratory distress, it can be attributed to stimulation of chemoreceptors and baroreceptors by SCs which increase bronchial airway resistance. Moreover, inhalation of xylene after SCs burn lead to bronchiolar damages and disrupt the alveolar surfactant leading to intra-alveolar hemorrhage and pulmonary edema with interference of gas exchange and resultant hypoxia and acidosis (Alon and Saint-Fleur, 2017).

The present study revealed that $12 \%$ of the cases had shock and $4.3 \%$ had cardiac arrhythmia. Statistical analysis revealed significant increase in shock, respiratory distress, mechanical ventilation, and cardiac arrhythmia in non-survivors. Similarly, Cooper (2016) reported that 11 patients out of 169 patients with SCs toxicity $(6.5 \%)$ reported cardiovascular effects and cardiogenic shock. These results are in accordance with Davis et al. (2015) who described cardiac arrest in association with inhaled synthetic cannabis, and Mir et al. (2011) who reported three patients presented to the emergency department complaining of chest pain after the use of synthetic cannabinoid and acute MI was diagnosed in each case based on electrocardiogram changes and elevated troponin levels.

It is well known that SCs had potent effects on cardiac conduction system, direct effect on ion channels and myocytes which result in abnormalities in inotropy, chronotropy, and conduction with resultant decrease cardiac output and dysrhythmias (Von Der Haar et al., 2016).

The laboratory result in this study revealed that $39 \%$ of the cases had metabolic abnormalities namely respiratory acidosis $(23 \%)$ and metabolic acidosis $(16 \%)$. Liver and renal impairment were recorded in $5 \%$ and $3 \%$ respectively. Statistical analysis revealed 
significant increase in metabolic acidosis and liver impairment in non-survivors. Similarly, Besli et al. (2015) on examining 16 patients with SCs toxicity reported that $40 \%$ presented with respiratory depression and respiratory acidosis, while Riederer et al. (2016) in their study of SCs patients found lower incidence of respiratory acidosis $5.4 \%$ and they also reported that $4 \%$ of the patients had acute kidney injury. Moreover Kamijo et al. (2014) in their retrospective study of 518 patients intoxicated by SCs in Japan found that liver dysfunction were detected in 25 patients $(4.8 \%)$ and renal dysfunction in 11 patients (2\%). Murat et al. (2018) found that increased liver enzyme levels $(15.9 \%)$ were the most common laboratory findings among SCs users. In contrast Abass et al. (2017) found no statistically significant difference in liver and kidney function tests between the SCs patient group and the control group in their study of 17 patients with SCs poisoning admitted to the Poisoning Control Unit (PCU) Zagazig University Hospitals from July 2015 to April 2016.

Respiratory acidosis can be attributed to decreased sensitivity of chemoreceptors to carbon dioxide and ventilation perfusion mismatch while metabolic acidosis can be attributed to hypoxia following seizures and shock (Wilkins et al., 2013). Although SCs action on cannabinoid receptors CB2 has been associated with liver disease, the exact mechanism of acute liver injury is unknown (Solimini et al., 2017). However, dose-related cumulative oxidative hepatocellular necrosis was proposed as a possible mechanism (Shahbaz et al. 2018).

The current study revealed that $78.3 \%$ of cases required ICU admission and this indicated severity of toxicity. Similarly Besli et al. (2015) on examining 16 patients with SCs toxicity found that $25 \%$ of the patients required ICU admission. Moreover Rech et al. (2015) reported that SCs are associated with higher rates of toxicity and hospital admissions than natural Cannabis, in contrast Murat et al. (2018) found that sever intoxication was diagnosed in only $7.6 \%$ SCs users. SCs are full agonists at the cannabinoid CB1 and CB2 receptor, so result in more potent effect than partial agonist effect of the natural cannabis, this responsible to more serious and sever course with more ICU admission in SCs toxicity (mills et al., 2015).

Recorded in -hospital mortality in this study was high $(11 \%)$ in comparison with other studies. The Mississippi State Department of Health reported more than 1200 SCs-related emergency visits with related 17 deaths and $1.4 \%$ mortality rates. Also, the Alabama Department of Public Health reported more than 1000 emergency visits with SCs toxicity and 5 related deaths with $0.5 \%$ mortality rates (Trecki et al. 2015). The higher incidence of severity and mortality in our results could be due to strox had different chemical structures and have unknown contaminants that varies from country to another and may interact by different way with different unpredictable effect.

\section{Conclusion:}

The incidence of strox toxicity has recently increased in Egypt with high mortality rate. Cardiac and respiratory complications are the most common causes of death. Until now little is known about the pattern of acute poisoning by strox poisoning, so early recognition of sever cases and close observation in ICU with early resuscitation could help in lowering the mortality rate.

\section{Recommendation:}

There is a need to increase awareness of synthetic cannabinoids hazards among general population. Physician should be trained to deal efficiently with SCs acute intoxication. Further studies are needed to elucidate the effects of THC analogues and to identify their most abundant constituents with subsequent successful detection.

\section{References:}

Alon M and Saint-Fleur M (2017): "Synthetic cannabinoid induced acute respiratory depression": Case series and literature review. Respiratory medicine case reports, 22:137-141.

Armstrong F, McCurdy MT, and Heavner MS (2019): Synthetic cannabinoid-associated multiple organ failure: case series and literature review. Pharmacotherapy: The Journal of Human Pharmacology and Drug Therapy, 39(4):508-13.

Atwood B, Lee D, Straiker A et al., (2011): "CP47, 497-C8 and JWH073, commonly found in 'Spice' herbal blends, are potent and efficacious CB (1) cannabinoid receptor agonists". Eur J Pharmacol, 659:139-145. [PubMed: 21333643].

Besli G, Ikiz M, Yildirim S et al., (2015): "Synthetic cannabinoid abuse in adolescents: a case series". The Journal of Emergency Medicine, 49(5): 644-650.

Bozkurt M, Umut G, Evren C et al., (2014): "clinical characteristics and laboratory test results of patients admitted to outpatient clinic for synthetic cannabinoids usage." The Journal of Psychiatry and Neurological Sciences, 27:328-334.

Cooper Z (2016): "Adverse Effects of Synthetic Cannabinoids: Management of Acute Toxicity and Withdrawal". Current Psychiatry Reports, 18(5):52.

Davis C and Boddington D (2015): "Teenage cardiac arrest following abuse of synthetic cannabis". Heart Lung Circ 24:162-163.

Farquhar C, Lefever T, Marusich J et al., (2018): "Molecular and Behavioral Pharmacological Characterization of Abused Synthetic Gamage Cannabinoids MMB- and MDMB-FUBINACA, MN-18, NNEI, CUMYL-PI CA, and 5-FluoroCUMYL-PICA". J Pharmacol Exp Ther, 365(2): 437-46.

Jesslin J, Adepu R and Churi S (2010): "Assessment of prevalence and mortality incidences due to poisoning in a South Indian tertiary care teaching hospital". Indian journal of pharmaceutical sciences, 72(5): 587. 
Kamijo Y, Takai, M, Fujita Y et al., (2014): "A multicenter retrospective survey of poisoning after consumption of products containing synthetic chemicals in Japan". Intern Med, 53: 2439-2445.

Lamy F, Daniulaityte R, Nahhas R et al., (2017): "Increases in synthetic cannabinoid-related harms: Results from a longitudinal, web-based control analysis. Int J Drug Policy, 44: 121-9.

Lapoint J, James L, Moran C et al., (2011). "Sever toxicity following synthetic cannabinoid ingestion". Clin Toxicol, 49:760-764.

Marc W, Amit R, Adriana J et al., (2017): "Clinical Characteristics of Synthetic Cannabinoid Use in a Large Urban Psychiatric Emergency Setting". Substance Use \& Misuse, 52: 822-825.

Abass M, Hassan M, Abd Elhaleem M, et al., (2017): "Acute Toxicity of a Novel Class of Hallucinogen "Voodoo" (Clinical and Experimental Study)". Ain Shams Journal of Forensic Medicine and Clinical Toxicology, 28: 62-71.

Mills B, Yepes A, and Nugent K (2015): "Synthetic cannabinoids". Am J Med Sci, 350(1):59-62.

Mir A, Obafemi A, Young A et al., (2011): "Myocardial infarction associated with use of the synthetic cannabinoid K2". Pediatrics, 128: $1622-1627$.

Murat Y, Nazlı T, Handan Y et al., (2018): "Sociodemographic and clinical characteristics of synthetic cannabinoid users in a large psychiatric emergency department in Turkey". Journal of Addictive Diseases, 37: 267-259:

Oznur T, Oznur H, Bolu, A et al., (2018): "Sociodemographic and Clinical Features of Young Adult Males Using Synthetic Cannabinoid." Turkish J Clinical Psychiatry, 21:15-23.

Rech M, Donahey E, Dziedzic J et al., (2015): "New drugs of abuse". Pharmacotherapy, 35(2):189197.

Riederer A, Campleman S,Carlson R. et al.,( 2016): "Acute Poisonings from Synthetic Cannabinoids - 50 U.S. Toxicology Investigators Consortium Registry Sites, 2010-2015". Morbidity and Mortality Weekly Report, 65 (27): 692-5.

Robinson T, Cheng F, Domingo C, et al., (2013): "Spicing up the differential for cyclical vomiting". American Journal of Gastroenterology, 108(8): 1371.

Sarah R.,Anna, M, Peter S et al., (2019): "Neuropsychiatric Sequelae in Adolescents with Acute Synthetic Cannabinoid Toxicity". Pediatrics, 144 (2): 122-125.
Schepis T, Desai R, Cavallo D et al., (2011): "Gender differences in adolescent marijuana use and associated psychosocial characteristics". J Addict Med, 5(1): 65-73.

Shafi A, Alex J, Harry S, et al., (2020): "New psychoactive substances: a review and updates". Therapeutic Advances in Psychopharmacology; 10: $1-21$

Shahbaz A, Rafael E, Muhammad F et al., (2018): "Acute Liver Injury Induced by Synthetic Cannabinoid". Abuse Cureus, 10(9): e3257.

Solimini R, Busardò F, Rotolo M et al., (2017): "Hepatotoxicity associated to synthetic cannabinoids use". PALMI, 21 (1 Suppl): 1-6.

Tai S, Hyatt W, Franks L et al., (2015): "Repeated administration of phytocannabinoid $\triangle 9$-THC or synthetic cannabinoids JWH-018 and JWH-073 induces tolerance to hypothermia but not locomotor suppression in mice and reduces CB1 receptor expression and function in a brain region-specific manner". Pharmacol Res, 102: 22-32. [PubMed: 26361728].

Taylor J (1990): "Statistical technique for data analysis". $2^{\text {nd }}$ ed., Lewis Pub. Inc., USA, PP: 2530.

Tellioglu T (2018): "Synthetic marijuana: what do we know about this recent hazard on the streets?" J Drug Abuse, 4: 1-2.

Trecki J, Gerona R, and Schwartz M (2015): "Synthetic cannabinoid-related illnesses and deaths". N Engl J Med, 373: 103-7.

Von Der Haar J, Talebi S, Ghobadi F et al., (2016): "Synthetic cannabinoids and their effects on the cardiovascular system". J Emerg Med, 50(2): 258-62.

Wilkins M, Williams K, Appel R, et al., (2013): Protien identification in Proteome projects. In: Proteome research: new frontiers in functional genomics,

Sobh ZK, and Sobh HK (2020): Strox "(Novel Synthetic Cannabinoids) in Egypt: Medical and Legal Challenges". Arab Journal of Forensic Sciences \& Forensic Medicine, Volume 2 (1): 57-60.

Ziva D (2016): "Adverse Effects of Synthetic Cannabinoids: Management of Acute Toxicity and Withdrawal". Curr Psychiatry Rep, 18(5): 52. 
ستروكس: دراسة لمدة r سنوات لحالات التسمم التى تم حجزها بمركز علاج التسمم بمستشفيات جامعة عين شمس تم حجز

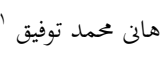

الملخص العربي

المقدمة: تعاطي القنب الصناعي هو مصدر قلق عالمي ، يخلق تحديات جديدة لخدمات العلاج. الاستروكس هو نسخة من شبائه القنب الصناعي ظهرت وأصبحت شائعة بشكل متز ايد في مصر.

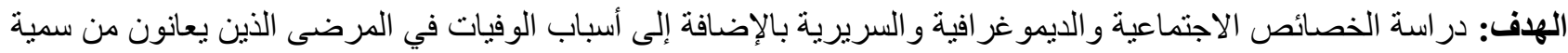

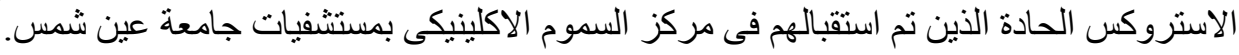

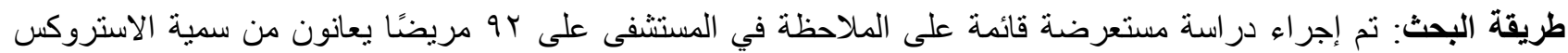

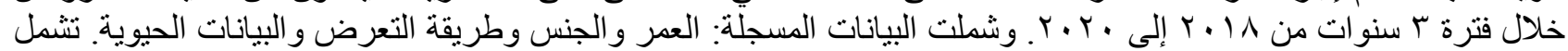

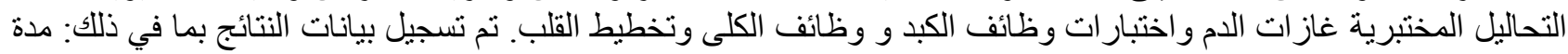
الإقامة في المستشفى ، ودخول وحدة العناية المركزة ومعدل الونات الوفيات.

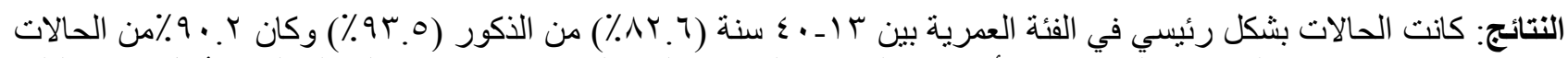

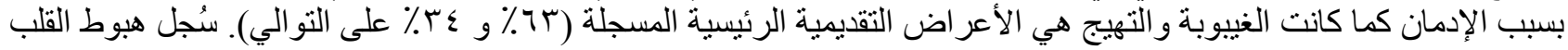

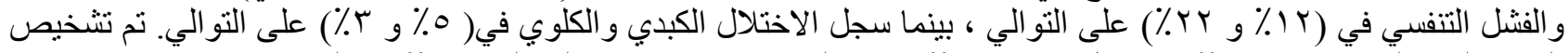

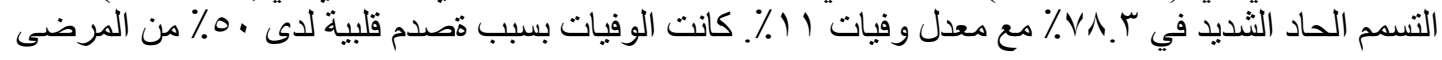

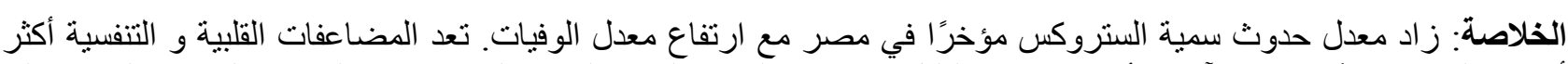

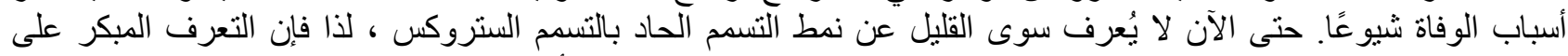
الحالات الثديدة والمر اقبة الدقيقة في وحدة العناية المركزة مع الإنعاش المبكر يمكن أن يساعد في خفض معدل الوفيات. 